\title{
Preface
}

\section{Understanding a Practice Venue}

\section{Gilbert I. Martin, MD}

Journal of Perinatology (2002) 22, S2 DOI: 10.1038/sj/jp/7210747

EVEN IN POPULOUS DISTRICTS THE PRACTICE OF MEDICINE IS A LONELY ROAD WHICH WINDS UPHILL ALL THE WAY AND A MAN MAY EASILY GO ASTRAY AND NEVER REACH THE DELECTABLE MOUNTAINS UNLESS HE EARLY FIND THOSE SHEPARD GUIDES OF WHOM BUNYAN TELLS, KNOWLEDGE, EXPERIENCE, WATCHFUL AND SINCERE

\section{Sir William Osler}

In thirty years of neonatal practice I have been in a multispecialty group practice, an academic university department, and a large single-specialty neonatal group. I have watched as our specialty practice matured from "anecdotal to evidence-based" and as reimbursement fell, documentation and "paper work" rose. I have noted a change in attitude of some young physicians who excelled with the knowledge of neonatal medicine and yet were disinterested in "community" and volunteer service to our local and national organizations.

Moving from practice to practice is not a new fad. However, the tools for understanding dissimilar methods, different management, and communication styles were never provided in our training. The correct answers have been few because the pertinent questions have oftentimes not been asked.

The clinical aspects of neonatology appear in many books and journals. The nonclinical factors appear in a few. This supplement to the Journal of Perinatology entitled UNDERSTANDING A PRACTICE VENUE describes various types of practices while at the same time suggests the proper questions to ask before making a final decision.

Sir William Osler describes the lonely, uphill road that we must follow in order to practice medicine. This treatise developed by the Committee on Practice Management (a subgroup of the Perinatal Section) can prevent us from going astray and to overcome the many nonclinical challenges we face every day. 